J. Amer. Soc. Hort. SCI.115(1):123-127. 1990.

\title{
Ethylene Production in Debladed Petioles from the Juvenile and Mature Phases of English Ivy in Relation to Adventitious Root Initiation
}

\author{
Robert L. Geneve ${ }^{1}$ \\ Department of Horticulture and Landscape Architecture, University of Kentucky, Lexington, \\ KY 40546 \\ Wesley P. Hackett ${ }^{2}$ and Bert T. Swanson ${ }^{2}$ \\ Department of Horticultural Science and Landscape Architecture, University of Minnesota, \\ St. Paul, MN 55108
}

Additional index words. Hedera helix, rooting, organogenesis, NAA, ACC

\begin{abstract}
Exogenous ethylene could not substitute for NAA to induce adventitious root initiation in juvenile petiole explants of English ivy (Hedera helix L.), indicating that the action of auxin-stimulated root initiation was not directly mediated through ethylene production. Mature petioles did not initiate roots under any auxin or ethylene treatment combination. Ethephon or ACC supplied at 50 or $100 \mu \mathrm{M}$ was inhibitory to NAA-induced root initiation in juvenile petioles. The pattern of ethylene production stimulated by NAA application was significantly different in juvenile and mature petioles. Ethylene evolution by juvenile petioles declined to near control levels during from 6 to 12 days after NAA application. Reduction in ethylene production was due to reduced availability of ACC in juvenile petioles. Mature petioles continued to produce ethylene at elevated levels throughout the course of the experiment. Ethylene does not appear to play a significant role in the differential root initiation response of juvenile and mature petioles treated with NAA. However, ethylene appeared to have an inhibitory effect during root elongation stages of adventitious root development in juvenile petioles. Chemical names used: 1-aminocyclopropane-1-carboxylic acid (ACC); 1-napthaleneacetic acid (NAA); 2-chloroethylphosphonic acid (ethephon).
\end{abstract}

Since early reports by Zimmerman et al. (25-27) that ethylene could stimulate root initiation in intact plants, researchers have investigated the significance of ethylene in adventitious root initiation in cuttings (see ref. 17 for review). In recent years, the mung bean bioassay has been used to study the role of ethylene in root initiation. Ethylene, supplied in the form of ethephon to mung bean cuttings, was shown to stimulate (12, $13,21,22)$, have no effect $(2,18)$, or be inhibitory $(8)$, to rooting. In studies in which ethylene evolution was measured there was no correlation between the levels of ethylene evolution from mung bean hypocotyl cuttings and the number of roots initiated per cutting $(2,7)$.

One inherent problem with the mung bean bioassay is the endogenous pool of $1 \mathrm{H}$-indole-3-acetic acid (IAA) in the cuttings (19). Mung bean cuttings have been shown to produce ethylene and adventitious roots without an exogenous supply of auxin $(2,9)$. The endogenous IAA pool makes it difficult to separate auxin and ethylene effects on root initiation from the effects of ethylene on transport and distribution of auxin in the cuttings $(3,4,16)$.

The objective of this study was to investigate the physiological significance of ethylene in controlling root initiation in an in vitro debladed petiole system using easy-to-root juvenile and difficult-to-root mature tissue of English ivy. The main advantage of this system, relative to the mung bean bioassay, is the ability to compare an easy-to-root juvenile tissue that requires auxin treatment (100 $\mu \mathrm{M}$ NAA optimum) for high-frequency root initiation (untreated cuttings do not root), with a difficult-

Received for publication 12 Sept. 1988. The cost of publishing this paper was defrayed in part by the payment of page charges. Under postal regulations, this paper therefore must be hereby markedadvertisement solely to indicate this fact.

'Assistant Professor.

${ }^{2}$ Professor. to-root mature tissue that forms root initials at a very low frequency in response to a wide range of auxin concentrations (9).

\section{Materials and Methods}

Debladed petioles from the juvenile and mature phases of a clone of English ivy were prepared as described previously (9). Briefly, the lamina was removed from the petiole of fully expanded leaves from juvenile and mature English ivy. Petioles were cut aseptically to a length of $2.3 \mathrm{~cm}$ and five petioles were placed in 25-ml Erlenmeyer flasks containing $1 \mathrm{ml}$ of liquid medium at $\mathrm{pH}$ 5.8. Ethephon was filter-sterilized and appropriate aliquots were added to the autoclave medium. NAA and ACC were autoclave with the standard assay medium. An aluminum foil cap was placed over each flask. Root formation was evaluated after 18 days of culture.

Ethylene evolution was measured from five petioles enclosed in a 25-ml Erlenmeyer flask that contained $1 \mathrm{ml}$ of medium. The flask was sealed with a rubber serum stopper. One-milliliter gas samples were taken from the head space every $24 \mathrm{hr}$ for 12 days (until roots were visible). The amount of ethylene measured was assumed to indicate the amount produced during 24 hr. After removing a gas sample, the serum stoppers were removed from the flasks for $15 \mathrm{~min}$ in a laminar flow hood to reduce the ethylene gas to ambient levels. Ethylene concentrations were measured with a Hewlett Packard 5880 A gas chromatograph fitted with a flame ionization detector and a Porapak Q 80- to 100-mesh column (Supelco, Bellefonte, Pa.) Ethylene levels were expressed as nanoliters produced over a $24-\mathrm{hr}$ period based on initial fresh weight. Each value presented in the results was the mean of two replicated samples and the values were representative of duplicate experiments.

Samples for ACC and 1-(malonylamino)cyclopropane-1-carboxylic acid (MACC) determinations consisted of five petioles weighing $\approx 410 \mathrm{mg}$ for juvenile petioles and $340 \mathrm{mg}$ fresh weight for mature petioles. The samples were ground in a mortar and 
pestle and extracted in $80 \%$ ethanol according to the methods of McKeon et al. (15); ACC was quantified as described by Lizada and Yang (14), except that $8 \mathrm{mmol}$ of $\mathrm{HgCl}_{2}$ was used. MACC was determined by measuring ACC before and after acid hydrolysis according to Hoffman et al. (10). The ACC increase after acid hydrolysis was assumed to be from MACC.

To estimate the activity of the ethylene-forming enzyme (EFE), $100 \mu \mathrm{M}$ of ACC was fed at time $0,3,6$, and 9 days to juvenile petioles treated with $100 \mu \mathrm{M}$ NAA $(5,15)$. Ethylene production was determined by gas chromatography as described above.

Juvenile and mature petioles were treated with $10 \mu \mathrm{l}$ ethylene/ liter by injection of a known quantity of standard in 25-ml Erlenmeyer flasks fitted with a rubber serum stopper. Each flask was vented and ethylene gas reintroduced every $24 \mathrm{hr}$. Ethylene was pulsed for 0 to 3,0 to 6,0 to 9,3 to 6,3 to 9 , and 6 to 9 days. The average number of roots per cutting was determined 18 days after the start of culture.

Juvenile petioles treated with $100 \mu \mathrm{M}$ NAA plus $10 \mu \mathrm{l}$ ethylene/liter for 3 to 9 days or $10 \mu \mathrm{M}$ of ACC alone were harvested at day 18, fixed in formalin : acetic acid : ethanol (FAA), and prepared for microscopic observation as described previously (9).

The statistical design for all experiments was a nested classification. The values presented for the mean number of roots per cutting were from representative experiments and were the means for 10 petioles in two replicated flasks.

\section{Results}

Juvenile and mature petioles treated with ACC or ethephon alone did not produce roots at the tested concentrations (Table 1). Juvenile petioles (but not mature petioles) treated with 100 $\mu \mathrm{M}$ NAA (optimum for rooting) or a combination of NAA + $\mathrm{ACC}$ or ethephon gave a rooting response. Increasing concentrations of ACC or ethephon in addition to the 100- $\mu$ M NAA treatment reduced the number of roots per cutting as compared to NAA treatment alone (Table 1). Low concentrations of ACC (1 to $10 \mu \mathrm{M}$ ) and ethephon $(1 \mu \mathrm{M})$ had no effect on auxinstimulated rooting. Ethephon was inhibitory to rooting at a lower concentration $(10 \mu \mathrm{M})$ than was ACC $(50 \mu \mathrm{M})$. Root initiation could not be induced in mature petioles with any of the tested combinations of NAA, ACC, or ethephon.

The addition of $10 \mu \mathrm{l}$ ethylene liter to NAA-treated juvenile petioles had no effect on root initiation when applied for 0 to 3 or 3 to 6 days (Fig. 1). A slight reduction in rooting was ob-

Table 1. Mean number of roots per juvenile petiole treated with various concentrations of ACC or ethephon with or without NAA for 18 days.

\begin{tabular}{|c|c|c|c|c|c|c|c|c|}
\hline \multirow[b]{3}{*}{ Treatment } & \multicolumn{5}{|c|}{$\begin{array}{c}\text { Concn of } \mathrm{ACC} \text { or } \\
\text { ethephon }(\mu \mathrm{M})\end{array}$} & \multicolumn{3}{|c|}{ Trend analysis } \\
\hline & 0 & 1 & 10 & 50 & 100 & Linear & Quadratic & \\
\hline & \multicolumn{5}{|c|}{ No./petiole } & \multicolumn{2}{|c|}{ F value } & $r^{2}$ \\
\hline \multirow{2}{*}{$\begin{array}{l}100 \mu \mathrm{M} \text { NAA }+ \\
\text { ethephon } \\
100 \mu \mathrm{MAA}+ \\
\text { ACC }\end{array}$} & 9.4 & 9.6 & 7.8 & 5.4 & 4.6 & $38.5^{* *}$ & $1.1^{\mathrm{Ns}}$ & 0.43 \\
\hline & 9.4 & 9.3 & 8.3 & 6.5 & 3.3 & $59.8^{* *}$ & $9.3^{* *}$ & 0.60 \\
\hline
\end{tabular}

zJuvenile petioles treated with ACC or ethephon alone failed to initiate roots. Mature petioles failed to initiate roots under any of these treatment combinations.

NS,**Nonsignificant at $P=0.05$ or significant at $P=0.01$, respectively.
15

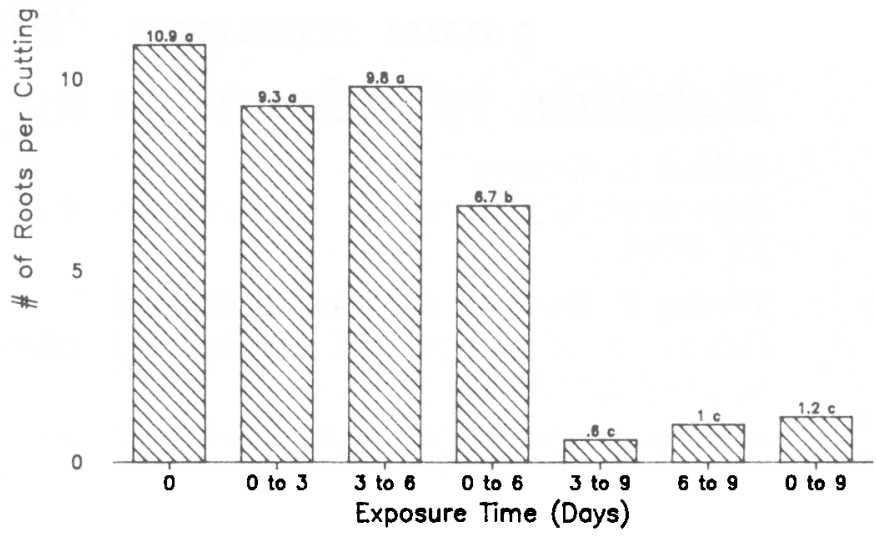

Fig. 1. Rooting response of juvenile petioles treated with $100 \mu \mathrm{M}$ NAA and exposed to $10 \mu \mathrm{l}$ ethylene/liter at various times after culture. The values represent the mean number of roots per petiole. Means followed by the same letter were not significantly different at the 0.05 level, as indicated by LSD.

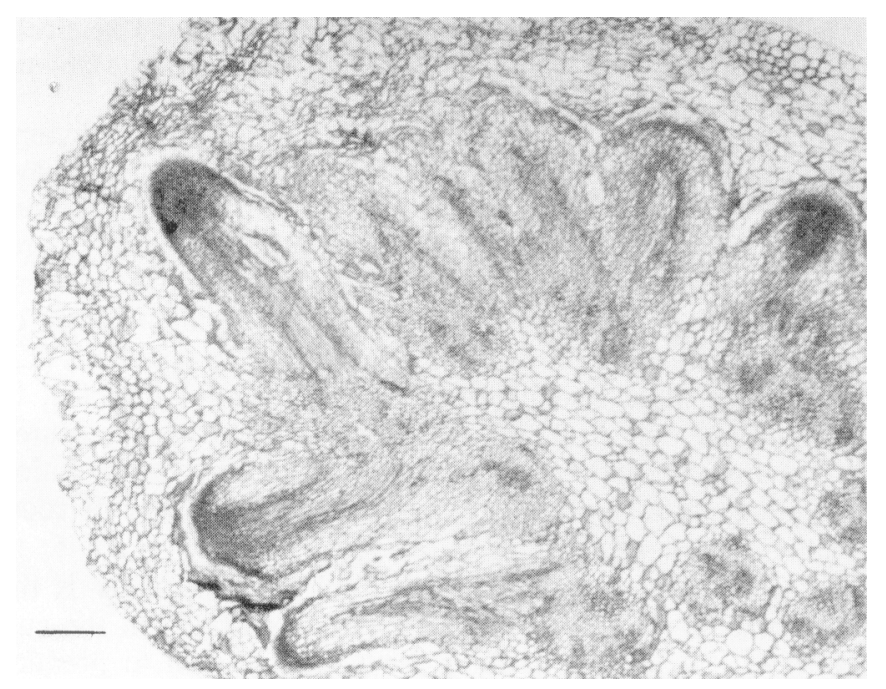

Fig. 2. Cross-sectional micrograph showing root primordia in a juvenile petiole treated with $100 \mu \mathrm{M}$ NAA that have failed to elongate by day 18 as a result of application of $10 \mu \mathrm{l}$ ethylene/liter from day 0 to 9 . Micrographs of petioles treated with ethylene for 0 to 9,3 to 9 , or 6 to 9 days showed similar root primordia development. Reference bar represents $200 \mu \mathrm{M}$.

served when ethylene was applied for 0 to 6 days. Ethylene added during 0 to 9,3 to 9 , and 6 to 9 days almost completely eliminated visible root formation. However, microscopic evaluation of these petioles revealed nine to 11 root primordia per cutting compared to the nine roots per cutting visible in NAAtreated cuttings (Fig. 2). The anatomy of NAA-treated petioles at day 9 and NAA-treated petioles pulsed with ethylene from 0 to 9 days show a similar stage of development indicating that the inhibitory effect of ethylene is on subsequent elongation of the root primordia. Microscopic observation of juvenile petioles treated with $100 \mu \mathrm{M}$ ACC alone show no evidence of root primordia or cell division (Fig. 3).

Ethylene alone did not stimulate rooting in juvenile petioles 


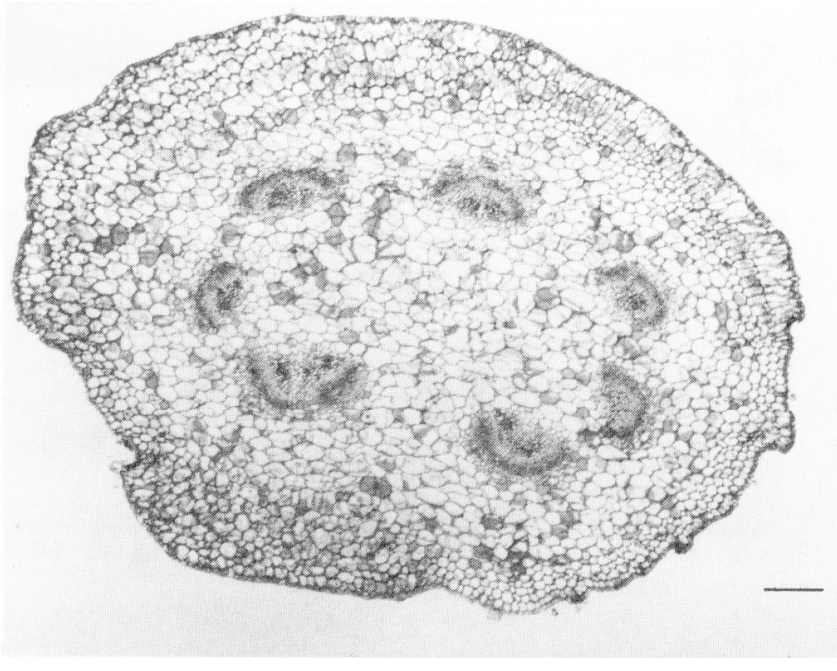

Fig. 3. Cross-sectional micrograph of a juvenile petiole treated with $100 \mu \mathrm{M}$ ACC only. Note that there was no evidence of root initiation or cell division. Reference bar represents $200 \mu \mathrm{M}$.

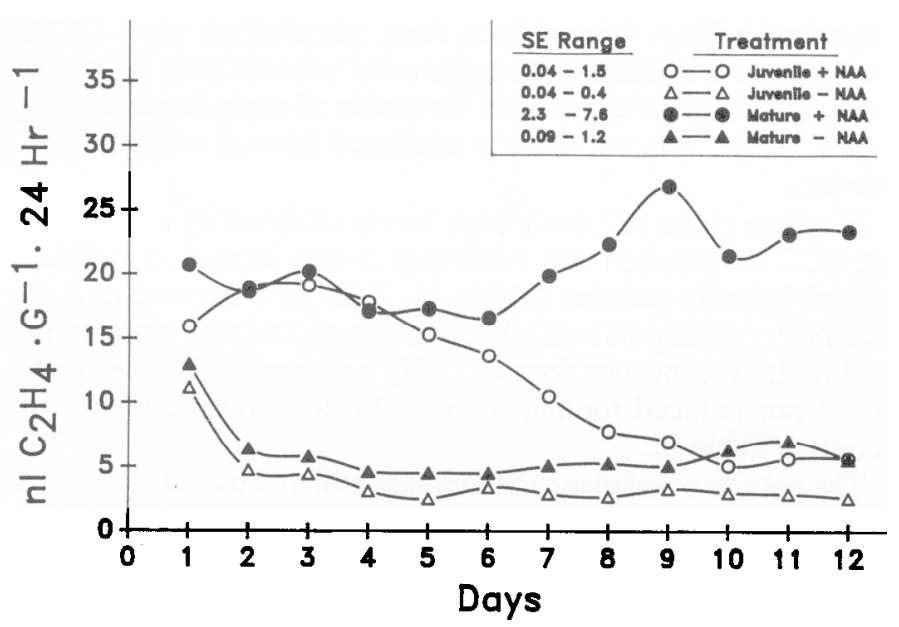

Fig. 4. Time, course for ethylene evolution in juvenile and mature petioles with and without auxin treatment. Standard error range indicates the minimum and maximum standard errors for the points in a treatment.

(data not presented). Ethylene alone or in combination with NAA did not stimulate root initiation in mature petioles (data not presented).

Ethylene evolution during repeated 24-hr periods for the first 12 days after treatment with $100 \mu \mathrm{M}$ NAA was different for juvenile and mature petioles (Fig. 4). The pattern of ethylene evolution was similar in the two phases for the first 5 to 7 days. However, at day 6, ethylene evolution began to decline in the juvenile petioles until day 10 , when it reached a level similar to control petioles (no NAA). The mature petioles did not show a decline in ethylene evolution at day 6 , but instead produced increasing amounts of ethylene for the remainder of the assay period. Petioles not treated with NAA produced very little ethylene (Fig. 4).

Treatment with the combination of $100 \mu \mathrm{M}$ ACC plus 100 $\mu \mathrm{M}$ NAA stimulated greater ethylene evolution in both juvenile and mature petioles than with NAA alone (Figs. 5 and 6). Eth-

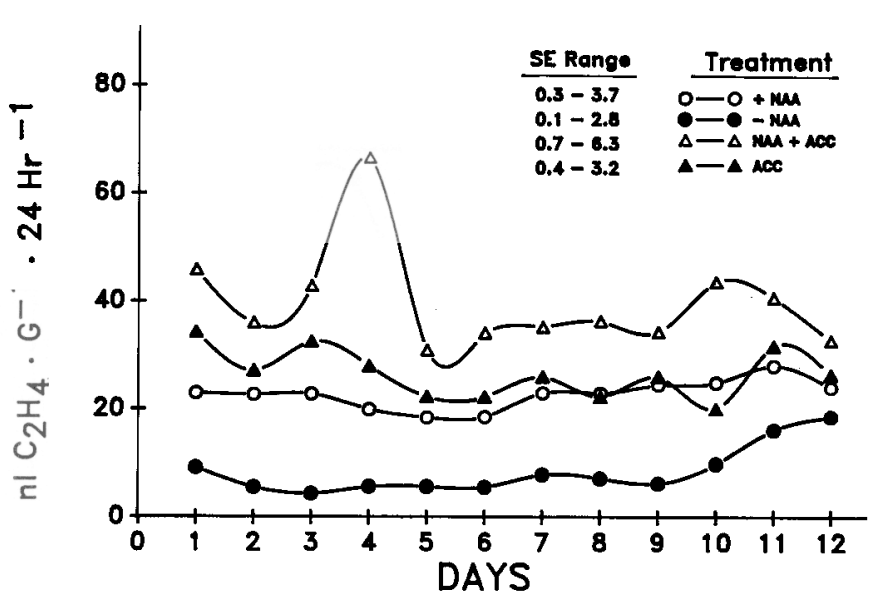

Fig. 5. Time course for ethylene evolution in mature petioles treated with $100 \mu \mathrm{M}$ ACC, $10 \mu \mathrm{M}$ NAA, or combination of the two. Standard error range indicates the minimum and maximum SES for the points in a treatment.

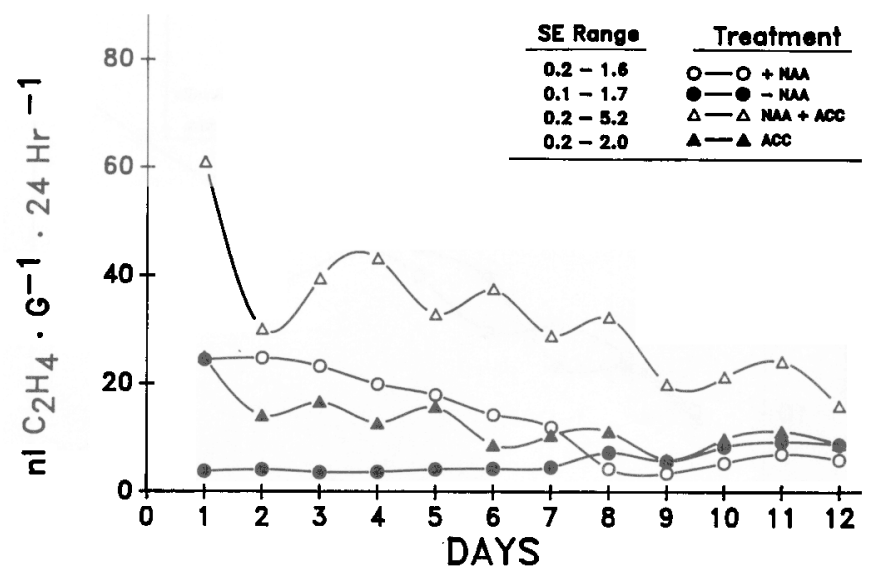

Fig. 6. Time course for ethylene evolution in juvenile petioles treated with $100 \mu \mathrm{M}$ ACC, $100 \mu \mathrm{M}$ NAA, or a combination of the two. Standard error range indicates the minimum and maximum SES for the points in a treatment.

ylene evolution was comparable for petioles treated with 100 $\mu \mathrm{M}$ NAA alone or $100 \mu \mathrm{M}$ ACC alone.

Total accumulation of ACC measured over 10 days showed a pattern similar to that for ethylene evolution in NAA-treated juvenile and mature petioles. ACC in juvenile petioles declined at day 6 (Fig. 7), paralleling the decline in ethylene evolution at day 6 (Fig. 4). In contrast, the ACC content of mature petioles did not decline at day 6 , but increased over the time course. This increase in ACC paralleled the increase in ethylene evolution per 24-hr period for mature petioles (Fig. 4).

The total amount of MACC accumulated in NAA-treated juvenile and mature petioles was substantially higher than the observed ACC content. MACC content for juvenile petioles increased for 6 days and stayed at that level for the remainder of the study (Fig. 8). However, MACC accumulation in mature petioles increased linearly throughout the 10 days of the experiment.

ACC at $100 \mu \mathrm{M}$ added to NAA-treated juvenile petioles at 0 , 3 , 6 , or 9 days stimulated ethylene production. The initial 24- 


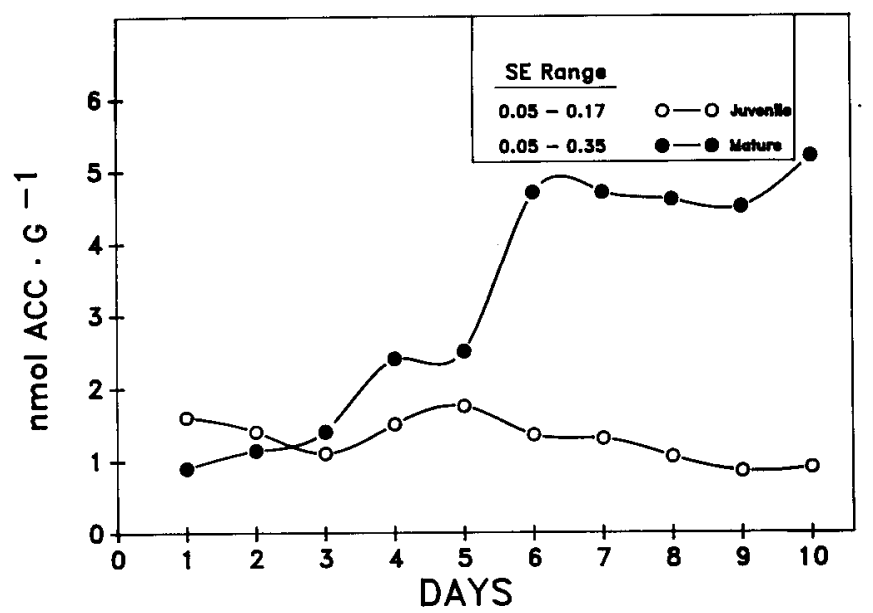

Fig. 7. ACC content in juvenile and mature petioles treated with 100 $\mu \mathrm{M}$ NAA. Standard error range indicates the minimum and maximum SES for the points in a treatment.

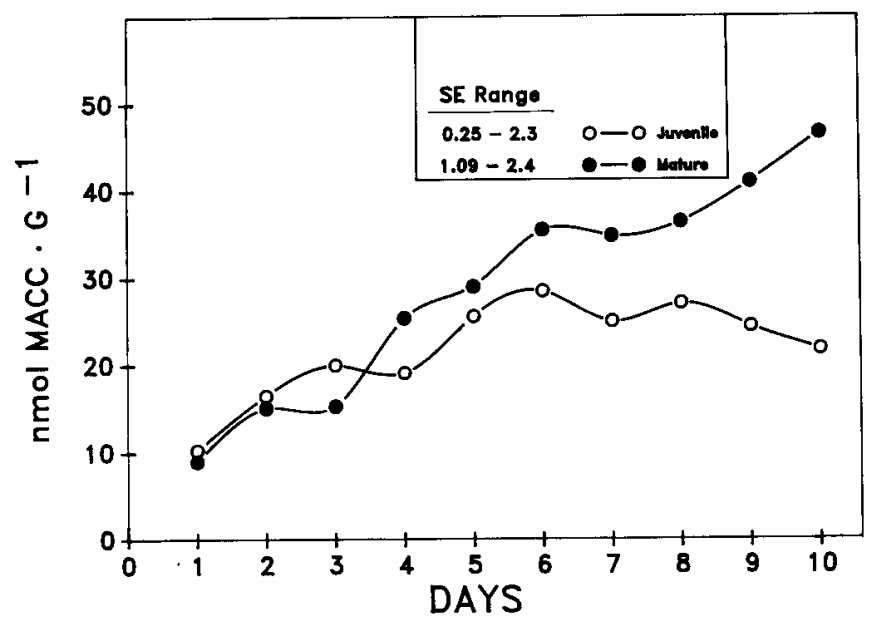

Fig. 8. MACC content in juvenile and mature petioles treated with $100 \mu \mathrm{M}$ NAA. Standard error range indicates the minimum and maximum SEs for the points in a treatment.

hr burst of ethylene produced following ACC application was $\approx 36.5 \mathrm{nl}$ ethylene/g fresh weight for each application time (Fig. $9)$.

\section{Discussion}

Several of the responses to auxin in plant systems can be attributed to auxin-induced ethylene production (1). It is often difficult to separate auxin effects from ethylene effects in the systems commonly used to study adventitious root initiation because stem cuttings contain an endogenous level of IAA sufficient to stimulate root initiation (19). Coleman et al. (6), using cultured tomato leaf disks that required exogenous auxin to form roots, observed no induction of rooting with ethylene or ethephon when supplied to non-auxin-treated disks. Similarly, induction of rooting did not occur in non-auxin-treated juvenile or mature English ivy petioles treated with ethylene, ACC, or ethephon (Table 1). Ethylene production by juvenile petioles treated with $100 \mu \mathrm{M}$ NAA alone or $100 \mu \mathrm{M}$ ACC alone was similar (Fig. 5) over the 12-day rooting period, but only petioles

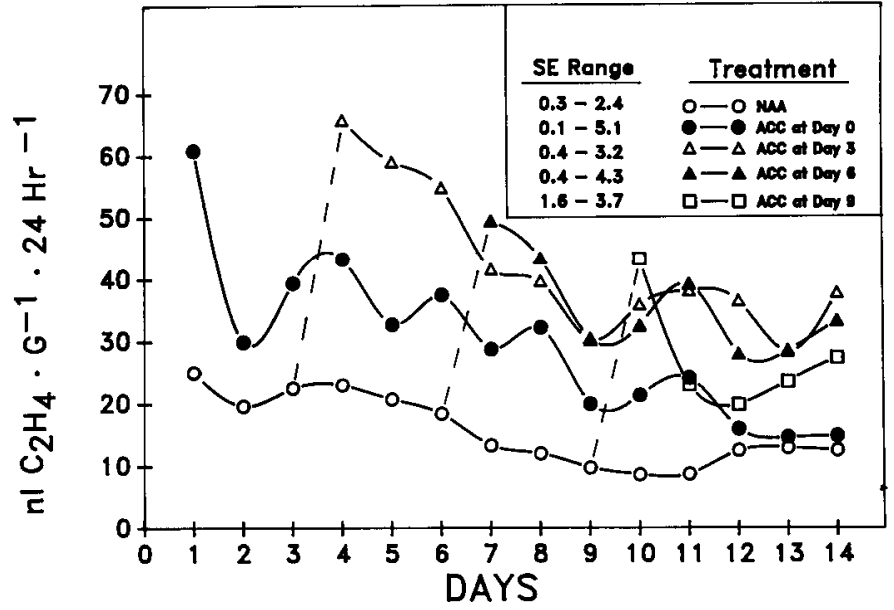

Fig. 9. The influence of ACC treatment at various times on ethylene evolution by juvenile petiole treated with $100 \mu \mathrm{M}$ NAA. Standard error range indicates the minimum and maximum SES for the points in a treatment.

treated with NAA were able to form adventitious roots (Table 1). These data indicate that ethylene did not substitute for auxininduced root initiation and that the action of auxin in stimulating root initiation was not directly mediated through ethylene production.

Ethylene at the relatively high levels obtained by administering ACC or ethephon was inhibitory to root formation in NAAtreated juvenile petioles (Table 1). This ethephon-induced reduction in rooting has also been observed in other systems $(6$, $8,20)$. Low concentrations of ACC or ethephon neither stimulated nor reduced rooting in NAA-treated juvenile or mature petioles (Table 1).

The pattern of ethylene evolution stimulated by $100 \mu \mathrm{M}$ NAA was different for juvenile and mature petioles (Fig. 4). There was a significant reduction in ethylene evolution from juvenile petioles beginning at days 5 to 6 , while an increase in ethylene evolution for NAA-treated mature petioles occurred from 6 to 12 days. This difference in ethylene production patterns was related to differences in availability of ACC for conversion to ethylene.

The biosynthesis of ethylene proceeds from S-adenosylmethionine to ACC to ethylene $(23,24)$. ACC can be converted to ethylene by the putative ethylene-forming enzyme (EFE) or ACC can be conjugated to MACC (24). In juvenile petioles treated with $100 \mu \mathrm{M}$ NAA, the reduction in ethylene evolution during days 6 to 12 was related to a reduction in available ACC (Fig. 7). Application of $100 \mu \mathrm{M}$ ACC to juvenile petioles at 0 , 3,6 , or 9 days gave no evidence of reduction in the ability of petioles to convert ACC to ethylene over time (Fig. 9). MACC is a stable conjugate of ACC that accumulates in plant tissues and does not act as a major storage pool for ACC and subsequent ethylene production (11). The time course for MACC production showed that the reduced availability of ACC in juvenile petioles at days 6 to 12 was not a result of increased conjugation of ACC, since petioles at this stage (6 to 12 days) were no longer accumulating MACC (Fig. 8). These results suggest that the reduction in ethylene evolution for juvenile petioles cultured 6 to 12 days was due to the reduced availability of ACC. The mature petioles showed an increase in ethylene production for 
days 6 to 12 concomitant with increased availability of ACC 11 . for that period (Fig. 7).

Ethylene evolution does not appear to play a significant role in the differential root initiation response observed for juvenile 12 and mature petioles. NAA-treated petioles from both phases produced similar amounts of ethylene during the first 6 days of 13 . culture, which corresponded to the initiation stage of root primordium formation in juvenile petioles, while only random cell divisions were initiated in mature petioles (9). However, the 14 reduction in ethylene production from days 6 to 12 juvenile petioles may have physiological significance since ethylene used at $10 \mu \mathrm{l} \cdot$ liter $^{-1}$ during days 0 to 9,3 to 9 , or 6 to 9 significantly 15 . reduced the number of roots observable by 18 days (Fig. 1). Anatomical investigation of these same petioles indicated that root primordia had been initiated, but failed to elongate with 16 . the elevated ethylene levels. These results suggest that reduced ethylene evolution may be a prerequisite for root initial out- 17 . growth.

\section{Literature Cited}

1. Abeles, F.B. 1973. Ethylene in plant biology. Academic, New York.

2. Batten, D.J. and M.G. Mullins. 1978. Ethylene and adventitious root formation in hypocotyl segments of etiolated mung bean (Vigna radiata) seedlings. Planta 138:193-197.

3. Beyer, E.M. and P.M. Morgan. 1971. Abscission: the role of ethylene modification of auxin transport. Plant Physiol. 48:208212.

4. Burg, S.P. and E.A. Burg. 1967. Lateral auxin transport in stems and roots. Plant Physiol. 32:891-893.

5. Cameron, A.C., C.A.L. Fenton, Y. Yu, D.O. Adams, and S.F. Yang. 1979. Increased production of ethylene by plant tissue treated with ACC. HortScience 14:178-180.

6. Coleman, W.K., T.J. Huxter, D.M. Red, and T.A. Thorpe. 1980. Ethylene as an endogenous inhibitor of root regeneration in tomato leaf discs cultured in vitro. Physiol. Plant. 48:519-525.

7. Geneve, R.L. and C.W. Heuser. 1982. The effects of IAA, IBA, NAA and 2,4-D on root promotion and ethylene evolution in mung bean. J. Amer. Soc. Hort. Sci. 107:202-205.

8. Geneve, R.L. and C.W. Heuser. 1983. The relationship between ethephon and auxin on adventitious root initiation in cuttings of Vigna radiata (L.) R. Wilcz. J. Amer. Soc. Hort. Sci. 108:330333.

9. Geneve, R.L., W.P. Hackett, and B.T. Swanson. 1988. Adventitious root initiation in de-bladed petioles from the juvenile and mature phase of English ivy. J. Amer. Soc. Hort. Sci. 113:630635.

10. Hoffman, N.E., Y. Liu, and S.F. Yang. 1983. Changes in MACC content in wilted wheat leaves in relation to their ethylene production rates and ACC content. Planta 157:518-523.
Jiao, X., S. Philosoph-Hadas, L. Su, and S.F. Yang. 1986. The conversion of 1-(malonylamino)cyclopropane-1-carboxylic acid in plant tissues. Plant Physiol $81: 637-641$.

Krishnamoorthy, H.N. 1970. Promotion of rooting in mung bean hypocotyl cuttings with ethrel, an ethylene releasing compound. Plant Cell Physiol. 11:979-982.

Krishnamoorthy, H.N. 1972. The effects of ethrel, auxin, and maleic hydrazide on the rooting of mung bean hypocotyl cuttings. Z. Pflanzenphysiol. 66:273-274.

Lizada, M.C.C. and S.F. Yang. 1979. A simple and sensitive assay for 1-aminocyclopropane-1-carboxylic acid. Anal. Biochem. 100:140-145.

McKeon, T.A., N.E. Hoffman and S.F. Yang. 1982. The effect of plant-hormone pretreatment on ethylene production and synthesis of 1-aminocyclopropane-1-carboxylic acid in water-stressed wheat leaves. Planta 155:437-443.

Morgan, P.W. and H.W. Gausman. 1966. Effects of ethylene on auxin transport. Plant Physiol. 41:45-52.

Mudge, K. 1989. Effect of ethylene on rooting. p. 150-161 In: T.D. Davis, B.E. Hassig, and N. Sonkhla (eds.). Adventitious root formation in cuttings, Dioscorides, Portland, Ore.

18. Mudge, K.G. and B. Swanson. 1978. The effect of ethephon, IBA and treatment solution $\mathrm{pH}$ on rooting and ethylene levels within mung bean cuttings. Plant Physiol. 61 :271-273.

19. Norcini, J.G., C.W. Heuser, and R.H. Hamilton. 1985. Changes in free and conjugated indole-3-acetic acid during initiation and early development of adventitious roots in mung bean. J. Amer. Soc. Hort. Sci. 110:528-532.

20. Nordstrum, A. and L. Eliasson. 1984. Regulation of root formation by auxin-ethylene interaction in pea stem cuttings. Physiol. Plant. 61:298-302.

21. Robbins, J.A., S.J. Kays, and M.A. Dirr. 1983. Enhanced rooting of wounded mung bean cuttings by wounding and ethephon. J. Amer. Soc. Hort. Sci. 108:325-328.

22. Roy, B.N., R.N. Basu, and T.K. Bose. 1972. Interaction of auxins with growth-retarding, -inhibiting, and ethylene producing chemicals in rooting of cuttings. Plant Cell Physiol. 12:11231127.

23. Yang, S.F. 1980. Regulation of ethylene biosynthesis. HortScience 15:238-243.

24. Yang, S.F. and N.E. Hoffman. 1984. Ethylene biosynthesis and its regulation in higher plants. Annu. Rev. Plant Physiol. 35:155180.

25. Zimmerman, P.W., W. Crocker, and A.E. Hitchcock. 1933. Initiation of roots from exposure of plants to carbon monoxide gas. Contrib. Boyce Thomson Inst. 5:1-17.

26. Zimmerman, P.W. and A.E. Hitchcock. 1933. Initiation and stimulation of adventitious roots caused by unsaturated hydrocarbon gases. Contrib. Boyce Thomson Inst. 7:209-230.

27. Zimmerman, P.W. and F. Wilcoxon. 1935. Several chemical growth substances which cause initiation of roots and other responses in plants. Contrib. Boyce Thomson Inst. 7:209-229. 